\title{
A Nonlinear Static Procedure for the Seismic Design of Symmetrical Irregular Bridges
}

\author{
Shanshan Li, ${ }^{1}$ Ping Xiang, ${ }^{1}$ Biao Wei ${ }^{1},{ }^{1}$ Lu Yan, ${ }^{1}$ and Ye Xia ${ }^{2}$ \\ ${ }^{1}$ School of Civil Engineering, Central South University, 22 Shaoshan South Road, Changsha 410075, China \\ ${ }^{2}$ Department of Bridge Engineering, Tongji University, 1239 Siping Road, Shanghai 200092, China
}

Correspondence should be addressed to Biao Wei; weibiao@csu.edu.cn

Received 1 May 2020; Revised 4 August 2020; Accepted 14 September 2020; Published 26 September 2020

Academic Editor: Marco Lepidi

Copyright (c) 2020 Shanshan Li et al. This is an open access article distributed under the Creative Commons Attribution License, which permits unrestricted use, distribution, and reproduction in any medium, provided the original work is properly cited.

Displacement-based seismic design methods support the performance-based seismic design philosophy known to be the most advanced seismic design theory. This paper explores one common type of irregular-continuous bridges and studies the prediction of their elastoplastic displacement demand, based on a new nonlinear static procedure. This benefits to achieve the operation of displacement-based seismic design. Three irregular-continuous bridges are analyzed to advance the equivalent SDOF system, build the capacity spectrum and the inelastic spectrum, and generate the new nonlinear static analysis. The proposed approach is used to simplify the prediction of elastoplastic displacement demand and is validated by parametric analysis. The new nonlinear static procedure is also used to achieve the displacement-based seismic design procedure. It is tested by an example to obtain results which show that after several combinations of the capacity spectrum (obtained by a pushover analysis) and the inelastic demand spectrum, the simplified displacement-based seismic design of the common irregular-continuous bridges can be achieved. By this design, the seismic damage on structures is effectively controlled.

\section{Introduction}

In recent years, displacement-based seismic design methods have rapidly developed, and the prediction of elastoplastic displacement demand on structures, under seismic action, has become a crucial issue [1]. Although inelastic time history analysis (ITHA) can calculate the elastoplastic displacement demand on structures, recent studies have concentrated on developing simplified methods for related questions due to the complexity of ITHA. In the present time, however, the mature simplified methods are primarily suitable for regular-continuous bridges, e.g., the pushover analysis method under uniform load in AASHTO [1]. When comparing irregular-continuous bridges [2] influenced by modes to the regular-continuous bridges, the simplified prediction methods of elastoplastic displacement demand require further study [3]. Although various of methodologies, such as the modal adaptive nonlinear static procedure (MANSP) [4-6], the modal pushover analysis (MPA) [7-10], and the incremental response spectral analysis (IRSA) [11], have been proposed, further investigation on their calculation accuracy, application scope, and the degree of simplification is needed.

In previous studies, some extremely irregular-continuous bridges were selected to validate the calculation accuracy $[12,13]$. Those bridges with asymmetry, obviously unequal pier length, and other irregular properties at the same time are common cases in mountain area or other similar areas. Regarding practical continuous bridges in general areas, cases with many regular factors and only few irregular factors [14], leading to the obvious influence of high modes, are referred to as the common irregular-continuous bridges. The irregular behavior comes from the dynamic response of the bridges under investigation despite these bridges having a rather regular geometric layout. In terms of common irregular-continuous bridges, the many rules in their seismic response benefit in finding a proper simplified prediction method of elastoplastic displacement demand.

In addition to the pushover-based analysis methods mentioned above, many other methods have been 
established for the simplified prediction of elastoplastic displacement demand in irregular-continuous bridges. For instance, Kowalsky proposed a displacement-based seismic design method, grounded in the ideas of equivalent system and equivalent damping ratio, etc. [15-18]. This proposed method involves the advantages of easy operation. Kappos, Gidaris, and Gkatzogias further improved some aspects of the proposed method $[19,20]$, such as how to combine the damping ratios of structural components to form the damping ratio of bridge systems. The ideas introduced in these methods are worth studying in the research of a new nonlinear static procedure analysis methods.

By taking one common type of irregular-continuous bridges in transverse direction as the object of study, this paper proposes a simplified prediction method of seismic displacement demand. Based on their seismic response characteristics (the equivalent system concept and the basic idea of pushover analysis), this paper also proposes the corresponding displacement-based seismic design procedure.

\section{A Common Type of Irregular- Continuous Bridges}

Regular-continuous bridges are generally defined as bridges that can be simplified as single-degree-of-freedom (SDOF) systems or as those with dynamic responses controlled by only a decisive fundamental mode. To carry out the simplified seismic design safely, the AASHTO [1] and China's Guidelines for Seismic Design of Highway Bridges (2008) define regular-continuous bridges according to structural characteristics. However, transverse dynamic responses of many actual continuous bridges are controlled by two or more modes. When this occurs, they are referred to as irregular-continuous bridges. Figure 1 shows one kind of the most popular irregular-continuous bridges containing many regular aspects, e.g., nearly symmetric distribution of pier length, nearly equivalent distribution of span length, and many other aspects which satisfy the structural requirements of regular-continuous bridges. However, the transverse dynamic response of these bridges is still controlled by two or more modes. This is due to the influence of the following irregular factors: (1) different pier lengths and a comparatively small stiffness ratio of girder to pier; (2) in order to prevent excessive internal forces and deformations at abutments under earthquakes, bidirectional sliding bearings are set on all abutments, as shown in Figure 1. Meanwhile, if the stiffness ratio of girder to pier is comparatively smaller, the mass of superstructure endured by each pier will be different under transverse seismic actions, even if the pier heights are nearly the same. In Figure 1, the modal shapes for the first and second modes are nearly identical in shape for the three different bridges. The reason is that the bidirectional sliding bearings are set on all abutments, and the stiffness ratio of girder to pier is small as described above, which control the first and second modes of the three different bridges. However, there are some differences in the bending degree of the corresponding vibration modes of the three bridges, since these bridges have different pier distributions. It is noted that shear keys are considered and designed in the transverse direction of abutments to meet the requirements under normal loading and their failure is only permitted under severe earthquakes [13].

The irregular-continuous bridges with relatively regular geometry are the study object of this paper. Three $4 \times 40 \mathrm{~m}$ typical, common irregular-continuous bridges in Figure 1 have been selected for analysis. The friction coefficient of sliding bearings is equal to 0.02 . The section properties of girders and columns are shown in Table 1. Earthquake load adopts the elastic response spectrum for soil profile III in Chinese criteria (JTJ 004-89), as shown in Figure 2(a). According to requirements of this paper, it is transformed in the following two ways: (i) it is converted into the inelastic demand spectrum, which will be used for the simplified prediction method of seismic displacement demand. The detailed procedure will be discussed in the following sections. (ii) To transform the ground motion input of ITHA, seven accelerograms are generated by the Simqke procedure [21]. Results of ITHA are regarded as the benchmark for comparison using the simplified prediction method. Figure 2(b) gives the first accelerogram while other figures are omitted due to similarity.

\section{Characteristics of Seismic Displacement}

The seismic displacement of girder is nearly symmetric for the common irregular-continuous bridges, and when induced by the gradual increase of peak ground accelerations (PGAs), its shape changes as the pier's yielding degree increases [22]. Furthermore, the shape will be relatively unchanged after the pier's yielding degree arrives at a given value. In this section, a concept of the equivalent system is used to decompose the girder's seismic displacement into the displacement of the equivalent SDOF system. The coefficient of displacement shape is applied to the foregoing three irregular-continuous bridges to study their characteristics of seismic displacement.

3.1. Concept of Equivalent SDOF System. To operate the pushover analysis and to carry out displacement-based seismic design procedure, it is necessary to first analyze how to transform a multi-degree-of-freedom (MDOF) system of a continuous bridge into a SDOF system, i.e., how to decompose the seismic displacement of the bridge into the displacement equivalent SDOF system and the coefficient of displacement shape.

In the finite element model (FEM), $m_{i}, \Delta_{i}, F_{i}$, and $a_{i}$ are defined to be the $i$ th structure node's mass, displacement, inertia force [23], and acceleration, respectively. The corresponding values of the equivalent SDOF system are denoted by $m_{\text {eq }}, \Delta_{\text {eq }}, F_{\text {eq }}$, and $a_{\text {eq }}$, respectively. The relationship between $\Delta_{i}$ and $\Delta_{\text {eq }}$, and $a_{i}$ and $a_{\text {eq }}$ is supposed as

$$
\begin{aligned}
& \Delta_{i}=c_{i} \Delta_{\mathrm{eq}}, \\
& a_{i}=c_{i} a_{\mathrm{eq}},
\end{aligned}
$$

where $c_{i}$ is the coefficient of displacement shape. 

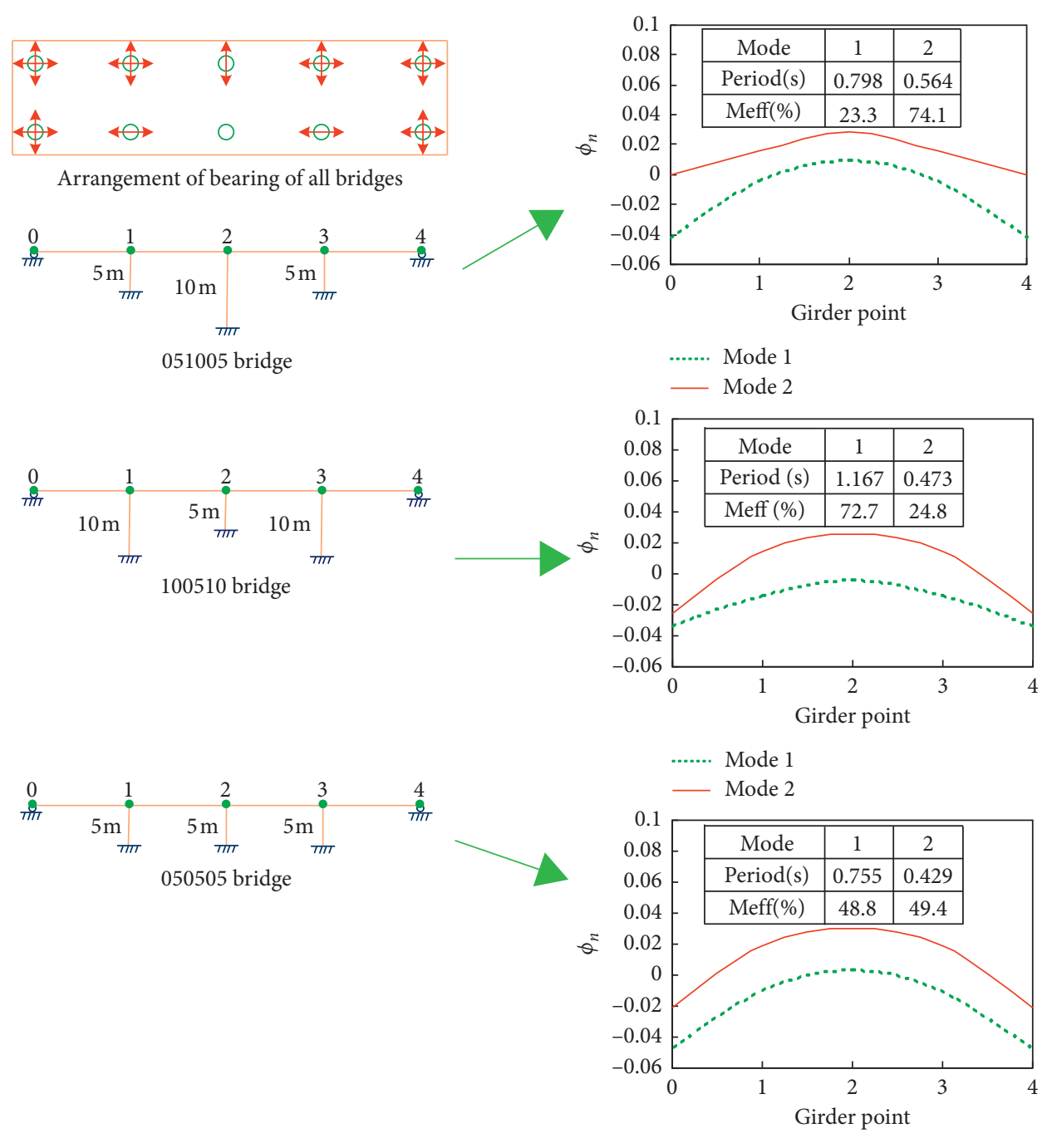

....... Mode 1

- Mode 2

FIgURE 1: One type of most popular irregular-continuous bridges.

TABLE 1: Section properties of girder and piers.

\begin{tabular}{lccccc}
\hline Components & $\begin{array}{c}\text { Area } \\
\left(\mathrm{m}^{2}\right)\end{array}$ & $\begin{array}{c}\text { Moment of inertia } \\
\left(\mathrm{m}^{4}\right)\end{array}$ & $\begin{array}{c}\text { Polar moment of inertia } \\
\left(\mathrm{m}^{4}\right)\end{array}$ & $\begin{array}{c}\text { Concrete } \\
\text { type }\end{array}$ & $\begin{array}{c}\text { Longitudinal reinforcement steel and area } \\
\text { ratio }\end{array}$ \\
\hline Girder & 7 & 40 & 14 & C50 & - \\
Column & 2.25 & 0.422 & 0.722 & C30 & HRB335, 0.66\% \\
\hline
\end{tabular}

The inertia force of the equivalent system is to be equal to the resultant inertia force of the original system; hence,

$$
F_{\mathrm{eq}}=\sum_{i=1}^{n} F_{i}=\sum_{i=1}^{n} m_{i} a_{i}=a_{\mathrm{eq}} \sum_{i=1}^{n} m_{i} c_{i}
$$

And thus, the mass of the equivalent system $m_{\mathrm{eq}}$ is denoted by

$$
m_{\mathrm{eq}}=\sum_{i=1}^{n} m_{i} c_{i}
$$

According to (2) and (3), it is obtained by

$$
F_{i}=m_{i} a_{i}=m_{i} c_{i} a_{\mathrm{eq}}=\frac{m_{i} c_{i}}{\sum_{i=1}^{n} m_{i} c_{i}} F_{\text {eq }}
$$

Substitute equation (1) into equation (5); hence,

$$
F_{i}=\frac{m_{i} \Delta_{i}}{\sum_{i=1}^{n} m_{i} \Delta_{i}} F_{\mathrm{eq}} .
$$

Suppose the inertia forces of the equivalent system and the original system to be equal, as follows: 


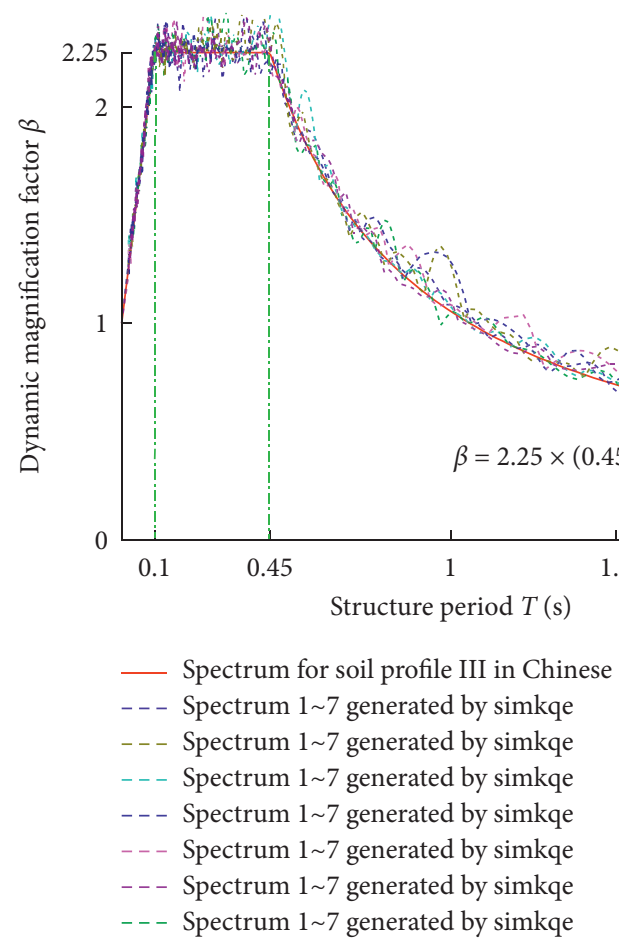

(a)

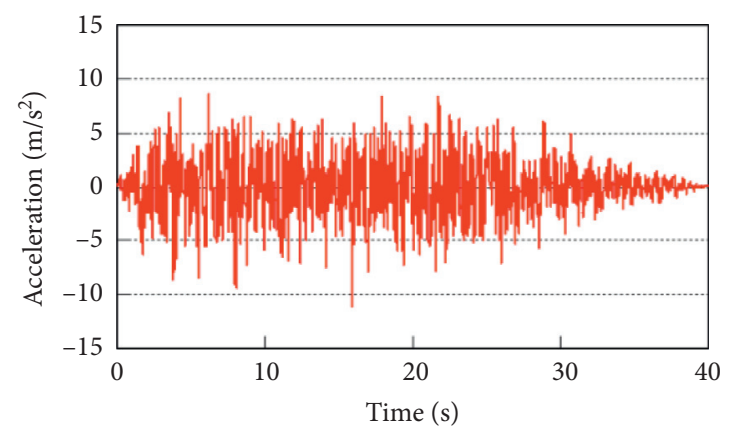

(b)

FIGURE 2: Earthquake input: (a) response spectra for soil profile III in Chinese criteria (JTJ 004-89) and generated by Simqke and (b) one accelerogram corresponding to (a).

$$
F_{\mathrm{eq}} \Delta_{\mathrm{eq}}=\sum_{i=1}^{n} F_{i} \Delta_{i}
$$

Substituting equation (6) into equation (7) obtains

$$
\Delta_{\mathrm{eq}}=\frac{\sum_{i=1}^{n} m_{i} \Delta_{i}^{2}}{\sum_{i=1}^{n} m_{i} \Delta_{i}}
$$

Substitute equation (8) into equation (1), and then

$$
c_{i}=\frac{\Delta_{i}}{\Delta_{\mathrm{eq}}}=\frac{\sum_{i=1}^{n} m_{i} \Delta_{i}}{\sum_{i=1}^{n} m_{i} \Delta_{i}^{2}} \Delta_{i} .
$$

Substitute equation (9) into equation (4); hence,

$$
m_{\mathrm{eq}}=\frac{\left(\sum_{i=1}^{n} m_{i} \Delta_{i}\right)^{2}}{\sum_{i=1}^{n} m_{i} \Delta_{i}^{2}} .
$$

Therefore, the relationship MDOF system being equivalent to the SDOF system is developed with the following characteristics:

(1) When a bridge structure is under elastic state, parameters $m_{\mathrm{eq}}, c_{i}$, and $\Delta_{\mathrm{eq}}$ are only related to the shape of the elastic displacement vector $\Delta$, which is equivalent to mode vector $\Phi_{n}$. Compared to a certain mode in multimode pushover analysis [8], $m_{\mathrm{eq}}$, in equation (10), similar to mode participation mass, $c_{i}$ in equation (9) is similar to the product of the mode participation factor $\Gamma_{n}$ and the corresponding value $\phi_{\text {in }}$ of the mode vector $\Phi_{n}$, and $\Delta_{\text {eq }}$ in equation (8) is similar to the response spectrum displacement $s_{d}$ of a certain single mode.

(2) When the bridge is under plastic state, $m_{\mathrm{eq}}, c_{i}$, and $\Delta_{\mathrm{eq}}$ are still related to the shape of the displacement vector $\Delta$.

(3) $\Delta$ can be decomposed into the product of $\Delta_{\text {eq }}$ and $c_{i}$ no matter what status the bridge is under, e.g., elastic state or plastic state.

3.2. Study Case. Displacement vector $\Delta$ of a bridge can be decomposed into the product of $\Delta_{\mathrm{eq}}$ and $c_{i}$ according to the foregoing concept of the equivalent system. It is used to study the seismic displacement characteristics of three irregular-continuous bridges in Figure 1.

FEM, for each bridge, is developed by OpenSees program [24]. The girders, piers, and bearings are simulated by elastic beam, fiber, and zero-length link elements, respectively. The cross section of piers is divided into three parts, including cover concrete, core concrete, and longitudinal bars. The concrete is simulated by concrete07, and the longitudinal bars are simulated by reinforcing steel material with the low-cycle fatigue parameters. The displacement-based fiber elements with adequate integral points are used to calculate the seismic responses. Different zero-length link elements are used to simulate the fixed and sliding bearings, respectively. As for the fixed bearings, the zero-length link element is an elastic link element with a large stiffness and an 
assumed large force which is unyielding forever. In terms of the middle and side sliding bearings, the zero-length link element is an elastoplastic link element with a yielding force of $75 \mathrm{kN}$ and $37.5 \mathrm{kN}$, respectively.

The accelerograms corresponding to the response spectrum of soil type III are designated for seismic input. 59 levels of PGA are investigated ranging from $0.02 \mathrm{~g}$ to $0.6 \mathrm{~g}$ with an interval of $0.01 \mathrm{~g}[25,26]$. The seismic displacement is calculated by ITHA. Parameters $m_{\mathrm{eq}}, \Delta_{\mathrm{eq}}$, and $c_{i}$ are determined by the concept of the equivalent system in Section 3.1.

The mass $m_{\mathrm{eq}}$ is computed by equation (10) and shown in Figure 3(a). As the total mass of each bridge is 3029, 3058, and 3000 tons, respectively, Figure 3(a) shows the following:

(1) The ratios of mass $m_{\mathrm{eq}}$ to bridge total mass are 94.8\% 96.7\%, 85.4\% 98.1\%, and 86.5\% 98.1\%, respectively. Therefore, with the inclusion of the participation masses of each mode, the mass $m_{\text {eq }}$ is nearly the same as the bridge total mass.

(2) The ratio of mass $m_{\mathrm{eq}}$ to bridge total mass for each bridge increases gradually as PGA increases, thus making $m_{\mathrm{eq}}$ closer to the bridge total mass.

The displacement $\Delta_{\text {eq }}$ is then computed by equation (8) and displayed in Figure 3(b). It shows that the displacement $\Delta_{\mathrm{eq}}$ for each bridge gradually increases as PGA increases. Figure 3(b) also shows that $\Delta_{\text {eq }}$ of the 051005 bridge and 050505 bridge almost coincides with each other since both trends increase at similar rates.

The coefficient of displacement shape $c_{i}$ is then computed by equation (9). $c_{i}$ of the girder points at $0 \#, 1 \#$, and $2 \#$ of each bridge in Figure 1 is shown in Figures 3(c)-3(e), illustrating how $c_{i}$ changes for each bridge along with the increase of PGA as follows:

(1) When PGA is small and the bridge is in an elastic state, the value of $c_{i}$ is stable as PGA increases

(2) When PGA is larger and the bridge begins to yield at different degrees, the value of $c_{i}$ changes rapidly as PGA increases

(3) When PGA is noticeably larger than case (2), the value of $c_{i}$ changes little and tends to stabilize as PGA increases

(4) The changing range of $c_{i}$ at the node 0 of the girder end, i.e., girder point 0 in Figure 1, is relatively smaller when compared to the corresponding value $c_{i}$ in its elastic state

\section{Procedure of Simplified Prediction of Seismic Displacement Demand}

This section gives a simplified prediction procedure of seismic displacement demand. The principle of the procedure is to combine the structural capacity spectrum and the inelastic demand spectrum to estimate the seismic displacement response of structure. The following will discuss each part of the simplified prediction procedure.

4.1. Capacity Spectrum. The transformation from seismic dynamic loading to static loading and the transformation from the MDOF system to the SDOF system must be studied in order to estimate the seismic displacement of the continuous bridge. In regard to studying the transformation from the MDOF system to the SDOF system, two main methods exist. One solution is the same as the multimode pushover analysis method, in which mode decomposition is executed and each mode refers to a single SDOF system. It can directly use the pushover analysis in theory. Because each important mode is used to determine the distribution of forces for the pushover analysis separately, this method is complex in practice. It also requires several pushover processes. The alternative method treats a continuous bridge as, approximately, a single SDOF system. It is pushed by reasonable distribution of forces, which have been indirectly adopted in the equivalent linear method. These forces will be used to build the capacity spectrum of irregular-continuous bridge in this section. This alternative method is simpler than the previous solution.

The relationship between the MDOF system and its equivalent SDOF system can be linked by the concept of the equivalent system according to the discussion in Section 3. Based on the above analysis, the following steps are used to obtain the capacity spectrum:

(1) The FEM of a bridge is analyzed by the response spectrum analysis to obtain the elastic displacement vector $\Delta$

(2) The bridge is pushed to a certain plastic state under the distribution of forces $m \Delta$, and the $V_{b}-u_{r}$ curve is obtained, where $V_{b}$ is the summation of shear force at the bottom of each pier and $u_{r}$ is the displacement of reference point, and $m$ is the mass matrix

(3) The $V_{b}-u_{r}$ curve is then transformed into the $S_{a}-S_{d}$ curve by assigning $S_{a}=V_{b} / m_{\mathrm{eq}}$ and $S_{d}=u_{r} / c_{i}$

This process of the pushover analysis method is referred to as the pushover analysis method based on response spectrum loads. For short, it is referenced to as RSP. Its basic idea comes from the $N 2$ method [27] and the FEMA pushover method [8], and some similar methods have been used for bridge structures [28, 29].

When the bridge is pushed by the distribution of forces $m \Delta$, the position of displacement reference point requires further discussion in this method. When the bridge is under elastic state, the displacement shape obtained by pushover analysis is nearly consistent with the shape of elastic displacement vector $\Delta . S_{d}=u_{r} / c_{i}$ of different displacement reference points is nearly the same with each other, and the corresponding $S_{a}-S_{d}$ curve is irrelevant to the position of the displacement reference point. However, when the bridge enters into plastic state, 

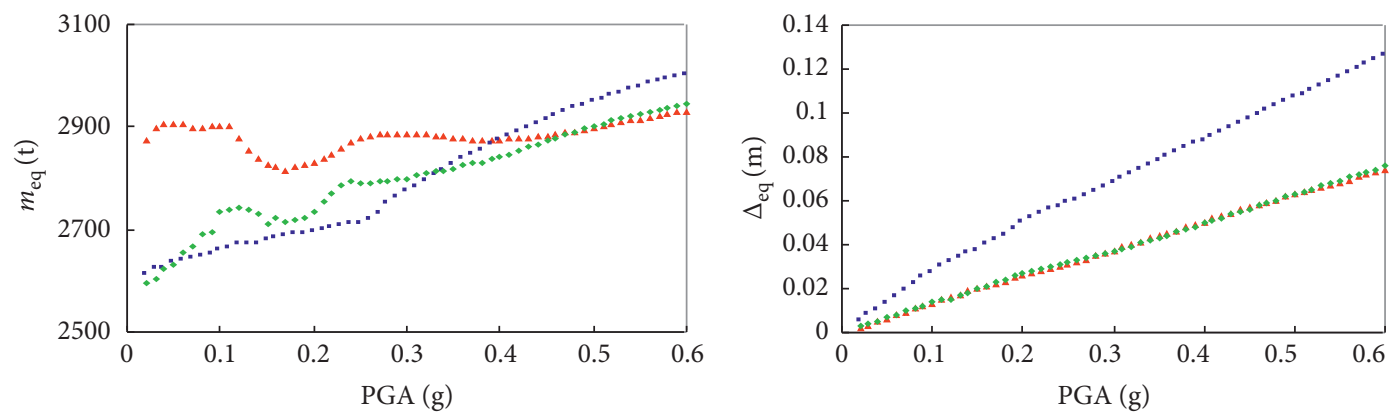

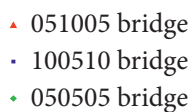

^ 051005 bridge

- 100510 bridge

- 050505 bridge

(a)

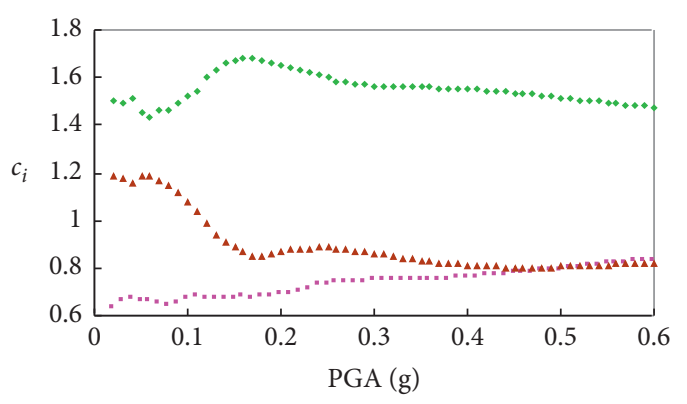

- Girder point 0

- Girder point 1

- Girder point 2

(c)

(d)

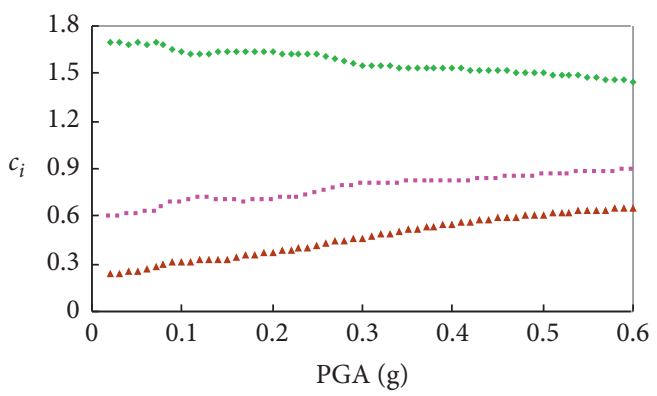

- Girder point 0

- Girder point 1

\ Girder point 2

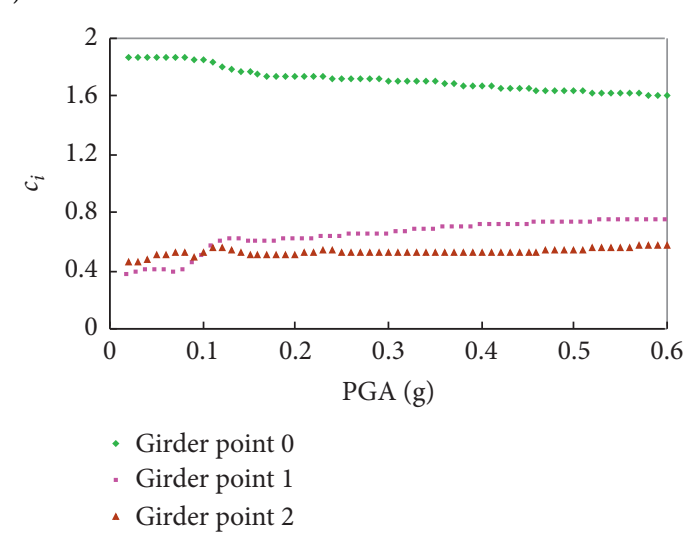

(e)

FiguRE 3: Equivalent SDOF system: (a) mass, (b) displacement, (c) coefficient of displacement shape of the 051005 bridge, (d) coefficient of displacement shape of the 100510 bridge, and (e) coefficient of displacement shape of the 050505 bridge.

the displacement shape (obtained by pushover analysis) and the shape of elastic displacement vector $\Delta$ (obtained by response spectrum analysis) become more and more inconsistent. Therefore, $S_{d}=u_{r} / c_{i}$ of different displacement reference points, is not the same. The corresponding $S_{a}-S_{d}$ curve is also different for various positions of displacement reference points.

Based on the concept of the equivalent system in Section 3 , vector $\Delta$ can be decomposed into the product of $\Delta_{\mathrm{eq}}$ and $c_{i}$. In pushover analysis, $u_{r}$ can be expressed as $u_{r}=c_{i} S_{d}$, in which $S_{d}$ is corresponding to $\Delta_{\mathrm{eq}}$ of an equivalent system from a physics concept. If the displacement vector $\Delta$ obtained by pushover analysis is required to be equal to the results from ITHA when $S_{d}=\Delta_{\text {eq }}$, the coefficient of displacement shape $c_{i}$ of the two methods must be the same. In the pushover analysis, $c_{i}$ is constantly changing, creating difficulty in tracking the complexity of its transformation. Thus, simplified measures are needed.

According to the case analysis in Section 3, the changing range of $c_{i}$ at the point 0 of the girder end is relatively smaller when compared to the corresponding value $c_{i}$ in its elastic state. Hence, the change of $c_{i}$ at the point 0 of the girder end 
under seismic actions is omitted, and the corresponding $c_{i}$ is assumed and set to be always equal to the value of elastic state. Therefore, the girder point 0 is chosen as the displacement reference point, and the $S_{a}-S_{d}$ curve of bridge structure can be obtained through the formula $S_{d}=u_{r} / c_{i}$, in which $u_{r}$ and $c_{i}$ are all the corresponding values of the girder point 0 .

4.2. Inelastic Demand Spectrum. Based on Section 2, the elastic response spectrum should be converted into the inelastic demand spectrum, used by the simplified prediction method of seismic displacement demand. The conversion can use $C$, the ratio of displacement demand of the elastoplastic model to that of its elastic counterpart for one SDOF system subjected to the same earthquake. Many researchers have investigated $C$ to simplify the estimation of seismic displacement demand of a structure [30,31], and $C$ used here adopts Miranda's equation shown as follows [32]:

$$
C=\left[1+\left(\frac{1}{\mu}-1\right) \cdot \exp \left(-12 T \mu^{-0,8}\right)\right]^{-1},
$$

where $T$ is the period of SDOF and $\mu$ is its displacement ductility demand.

The aforementioned elastic response spectrum is converted as follows:

$$
\begin{aligned}
S_{a y} & =\frac{\mathrm{CS}_{a}}{\mu}, \\
S_{u} & =\mathrm{CS}_{d}=\frac{\mathrm{CS}_{a} T^{2}}{4 \pi^{2}},
\end{aligned}
$$

where $S_{d}$ and $S_{a}$ are, respectively, the displacement value and acceleration value of the elastic response spectrum. $S_{u}$ and $S_{a y}$ are, respectively, the displacement value and acceleration value of the inelastic response spectrum.

Figure 4 shows how to construct the inelastic demand spectrum based on the aforementioned equations. Therefore, the inelastic demand spectrum and the aforementioned capacity spectrum can be applied to the $S_{a}-S_{d}$ coordinate system to obtain the modal displacement response $S_{d}$ [33].

4.3. Prediction of Seismic Displacement. The inelastic demand spectrum and the capacity spectrum are drawn in the same figure. The capacity spectrum will intersect with different demand spectrums corresponding to different $\mu$ values, which are the displacement ductility demand factor. Different $S_{d}$ of the intersection points will then also be obtained. Denote $\mu^{\prime}$ as $S_{d} / S_{d y}$, where $S_{d y}$ is the spectrum value of yield-point displacement and $\mu^{\prime}=1$ when $S_{d}$ is in the elastic region. The $S_{d}$ of the intersection point corresponding to $\mu \approx \mu^{\prime}$, where $\mu$ is the displacement ductility demand in Figure 4 and $\mu^{\prime}=S_{d} / S_{d y}$ in the capacity spectrum, is the seismic displacement demand of the equivalent SDOF system. $S_{d}$ is equivalent to $\Delta_{\mathrm{eq}}$ in equation (8).

Seismic displacement demand $\Delta_{i}$ of each node in its original structure needs to be reversely solved by using equation (1) after obtaining the $S_{d}$ or $\Delta_{\mathrm{eq}}$ of the equivalent
SDOF system in theory. As to further simply the prediction of displacement demand in practice, it adopts the actual pushover displacement vector $u$, corresponding to $S_{d}$, as the seismic displacement demand $\Delta_{i}$ of each node in the bridge system.

\section{Verification Case of Simplified Prediction Procedure}

Results show that the seismic displacement response of irregular-continuous bridges has two characteristics as PGA increases: (1) the displacement $\Delta_{\mathrm{eq}}$ of the equivalent SDOF system increases gradually and (2) the coefficient $c_{i}$ of displacement shape is constantly changing. The two characteristics above should be reflected when judging if a simplified prediction method can correctly predict the seismic displacement response of irregular-continuous bridges. In this part, RSP is applied to three irregularcontinuous bridges in Figure 1 to verify the effectiveness of the simplified prediction method proposed in Section 4.

5.1. Characteristics of RSP. Based on the concept of the equivalent system, the displacement vector $\Delta$ can be decomposed into the product of $\Delta_{\mathrm{eq}}$ and $c_{i}$. If RSP correctly predicts the seismic displacement response of irregularcontinuous bridges, it must have the following characteristics:

(1) $S_{d}$ from RSP must be almost consistent with $\Delta_{\text {eq }}$ from ITHA

(2) Displacement shape from RSP must reflect the changes of $c_{i}$ from ITHA

Taking irregular-continuous bridges in Figure 1 as an example, the seismic displacement is solved by RSP and ITHA, respectively. They are compared with each other to verify RSP's validity. The detailed processes are as follows:

(1) FEM of each bridge is built in OpenSees program, in which elastic beam element, fiber element, and nonlinear link element are used to simulate the girder, the piers, and the bearings. The Chinese response spectrum of soil type III in Figure 2(a) and the corresponding accelerograms in Figure 2(b) are chosen as the earthquake input. PGA is divided into 59 levels from $0.02 \mathrm{~g}$ to $0.6 \mathrm{~g}$ by intervals of $0.01 \mathrm{~g}$.

(2) The seismic displacement for each seismic level is calculated by ITHA, and the corresponding displacement $\Delta_{\text {eq }}$ of the equivalent SDOF system is obtained by equation (8).

(3) $S_{d}$ of the equivalent SDOF system is calculated by RSP for each seismic level, and the corresponding pushover displacement vector $\mathbf{u}$ is adopted as the seismic displacement of the bridge.

(4) $S_{d}$ from RSP and $\Delta_{\text {eq }}$ from ITHA are compared as shown in Figure 5.

(5) Seismic displacements from RSP and ITHA for the same $S_{d}$ or $\Delta_{\text {eq }}$ are compared as shown in Figure 6. 


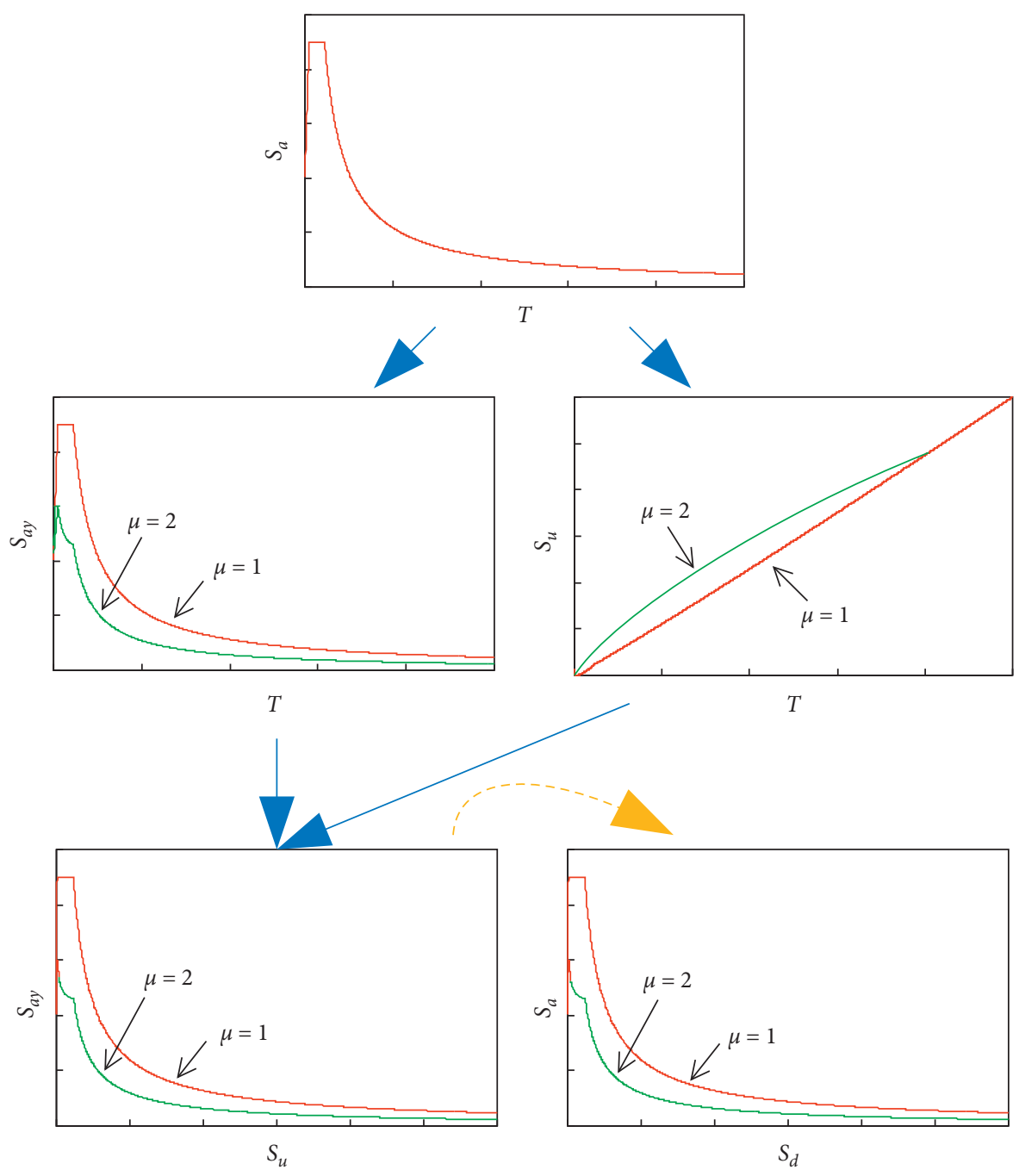

FIGURE 4: Generation procedure of the inelastic demand spectrum. follows:

According to Figure 5, some conclusions are obtained as

(1) As a whole, $S_{d}$ calculated by RSP is close to $\Delta_{\text {eq }}$ by ITHA

(2) The difference between $S_{d}$ and $\Delta_{\text {eq }}$ becomes more and more obvious as PGA increases, and $S_{d}$, calculated by RSP, is larger

Based on Figure 6, some conclusions are obtained as follows:

(1) In general, as for the same displacement of the equivalent SDOF system, seismic displacement from RSP is close to the one from ITHA. This indirectly shows that the displacement shape from RSP can reflect the changes of $c_{i}$ from ITHA based on equation (9).

(2) The difference between seismic displacement from RSP and that from ITHA becomes more obvious as a whole, as PGA increases.

Results from Figures 5 and 6 show that the simplified prediction method, proposed in Section 4, can be used to predict seismic displacement for the irregular-continuous bridges of the case study.

As to evaluate the prediction errors of the simplified prediction method in detail, the Chinese response spectrum of soil type III in Figure 2(a) and the corresponding accelerograms in Figure 2(b) are chosen as the earthquake input for the irregular bridges in Figure 1, and PGA adopts $0.1 \mathrm{~g}, 0.2 \mathrm{~g}, 0.4 \mathrm{~g}, 0.8 \mathrm{~g}$, and $1.6 \mathrm{~g}$, respectively. The corresponding results are shown in the following sections.

5.2. Case 1: 051005 Bridge. As for the 051005 bridge, taking PGA of $a=0.2 \mathrm{~g}$, for example, the procedure for seismic displacement prediction is described in detail, shown in Figure 7.

In Figure 7, the girder end point 0 is chosen as the displacement reference point. The capacity spectrum is obtained by pushing the bridge under the response spectrum load distribution, in which the spectrum value of yield-point displacement is $S_{d y}=0.021 \mathrm{~m}$. The values of $S_{d}$ for the three intersection points of the capacity spectrum curve and three demand spectrum curves with $\mu=1.0,1.5$, and 2.0 are $0.055 \mathrm{~m}$, $0.032 \mathrm{~m}$, and $0.029 \mathrm{~m}$, respectively. The corresponding values of 


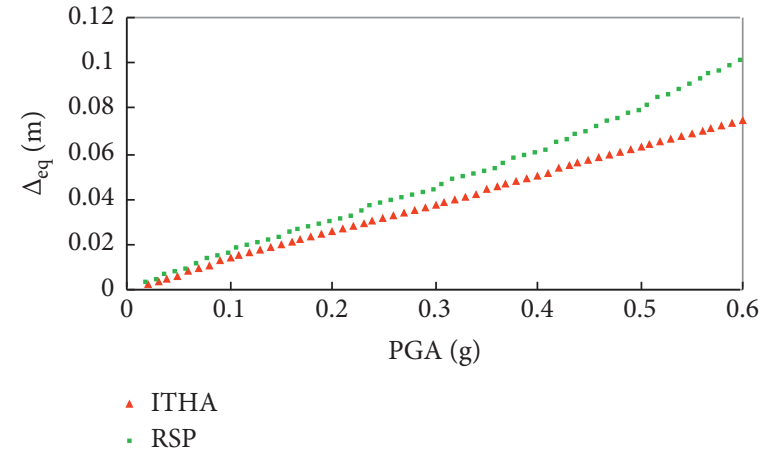

(a)

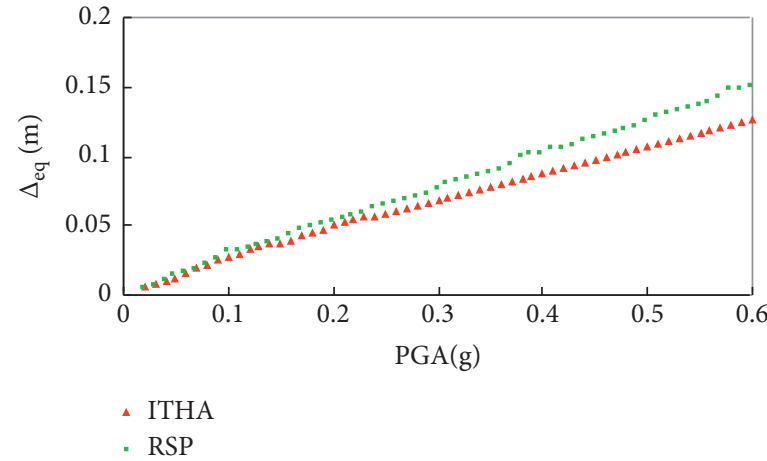

(b)

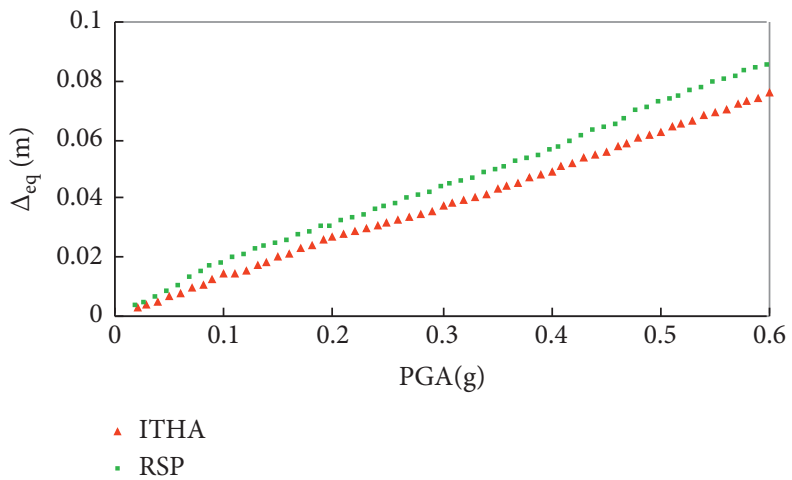

(c)

FIGURE 5: Comparison of the equivalent SDOF system's displacement by ITHA and RSP: (a) 051005 bridge, (b) 100510 bridge, and (c) 050505 bridge.

$\mu^{\prime}=S_{d} / S_{d y}$ are $2.62,1.53$, and 1.38 , respectively. Note that $\mu \approx \mu^{\prime}$ is only satisfied when $\mu=1.5$; hence, $S_{d}$ of the equivalent SDOF system is $0.032 \mathrm{~m}$. According to the result of pushover analysis, the values of seismic displacement of the girder points of $0 \#, 1 \#, 2 \#, 3 \#$, and $4 \#$ corresponding to $S_{d}=$ $0.032 \mathrm{~m}$ are $0.045 \mathrm{~m}, 0.018 \mathrm{~m}, 0.024 \mathrm{~m}, 0.018 \mathrm{~m}$, and $0.045 \mathrm{~m}$, respectively. The corresponding values of ITHA are $0.042 \mathrm{~m}$, $0.016 \mathrm{~m}, 0.021 \mathrm{~m}, 0.016 \mathrm{~m}$, and $0.042 \mathrm{~m}$, respectively. The results show that the seismic displacement of the simplified prediction method is close to that of ITHA.

The comparison of seismic displacement calculated by the simplified prediction method using RSP and that by ITHA, under five PGA levels of $a=0.1 \mathrm{~g}, 0.2 \mathrm{~g}, 0.4 \mathrm{~g}, 0.8 \mathrm{~g}$, and $1.6 \mathrm{~g}$, is shown in Figure 8(a). For each PGA level, the seismic displacement calculated by the simplified prediction method using RSP is close to that of ITHA. Even for the PGA level of $a=1.6 \mathrm{~g}$, the maximum relative error of the seismic displacement of the simplified prediction method using RSP is only $16 \%$ when compared to that of ITHA. This can satisfy the engineering application. It is meaningless for the PGA level of $a=1.6 \mathrm{~g}$, since most bridges will not suffer such a strong earthquake. Such a case is only used to identify the accuracy of the simplified prediction method using RSP.

5.3. Case 2: 100510 Bridge. As for the 100510 bridge, the comparison of seismic displacement calculated by the simplified prediction method using RSP and that by ITHA is shown in Figure 8(b). In terms of the PGA level of $a=0.1 \mathrm{~g}$, $0.2 \mathrm{~g}, 0.4 \mathrm{~g}$, and $0.8 \mathrm{~g}$, the ratio of seismic displacement of the simplified prediction method using RSP to that of ITHA ranges from $85 \%$ to $118 \%$, which can meet the requirement of the engineering application. At a PGA level of $a=1.6 \mathrm{~g}$, the ratio of seismic displacement of the simplified prediction method using RSP to that of ITHA ranges from $75 \%$ to $130 \%$, which shows that as PGA increases, the relative error of the seismic displacement of the simplified prediction method using RSP increases when compared to that of ITHA.

5.4. Case 3: 050505 Bridge. As for the 050505 bridge, the comparison of seismic displacement calculated by the simplified prediction method using RSP and that by ITHA is shown in Figure 8(c). In terms of the PGA level of $a=0.1 \mathrm{~g}$, $0.2 \mathrm{~g}, 0.4 \mathrm{~g}$, and $0.8 \mathrm{~g}$, the ratio of seismic displacement of the simplified prediction method using RSP to that of ITHA ranges from $85 \%$ to $119 \%$, which can meet the requirement of engineering application. At a PGA level of $a=1.6 \mathrm{~g}$, the ratio of seismic displacement of the simplified prediction method using RSP to that of ITHA ranges from $98 \%$ to $130 \%$, which shows that as PGA increases, the relative error of the seismic displacement of the simplified prediction method using RSP increases when compared to that of ITHA. 

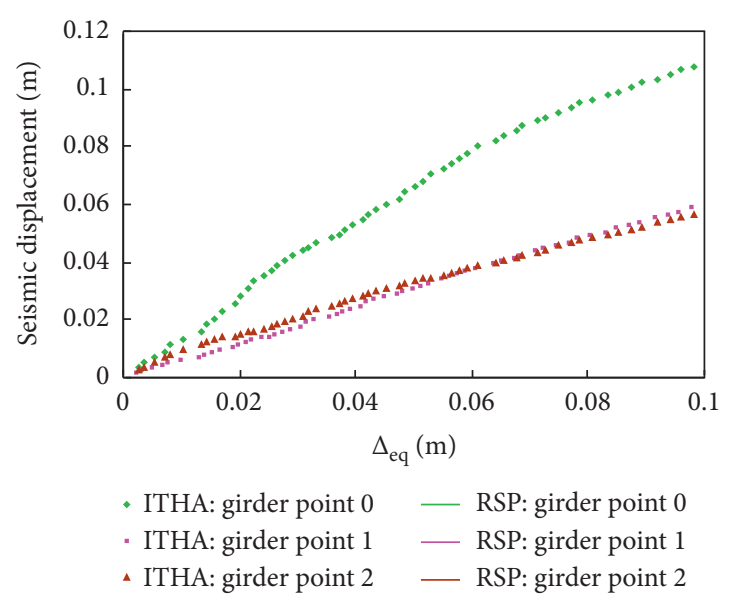

(a)

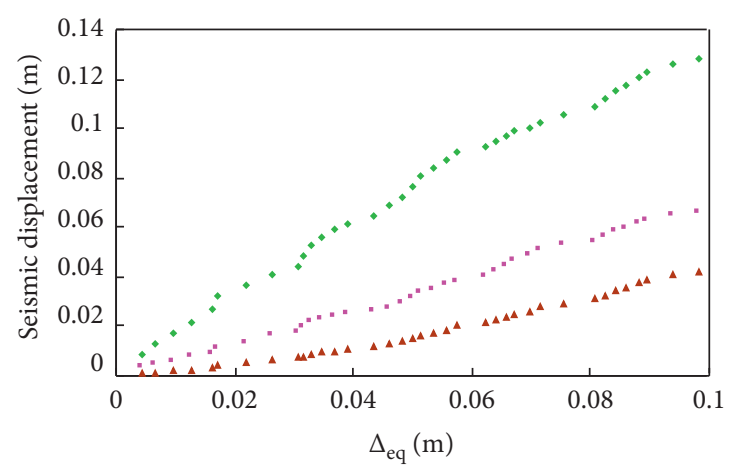

- ITHA: girder point $0-$ RSP: girder point 0

- ITHA: girder point 1 RSP: girder point 1

॥ ITHA: girder point $2 \_$RSP: girder point 2

(b)

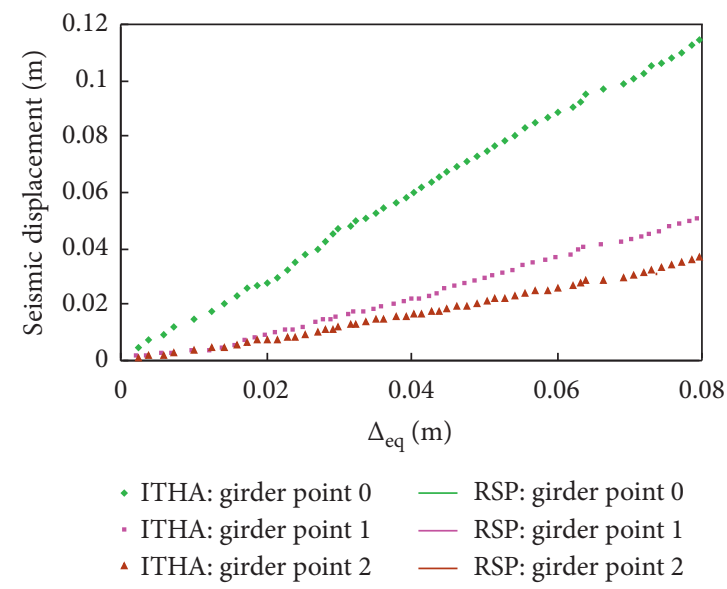

(c)

FIgURE 6: Comparison of seismic displacement by ITHA and RSP: (a) 051005 bridge, (b) 100510 bridge, and (c) 050505 bridge.

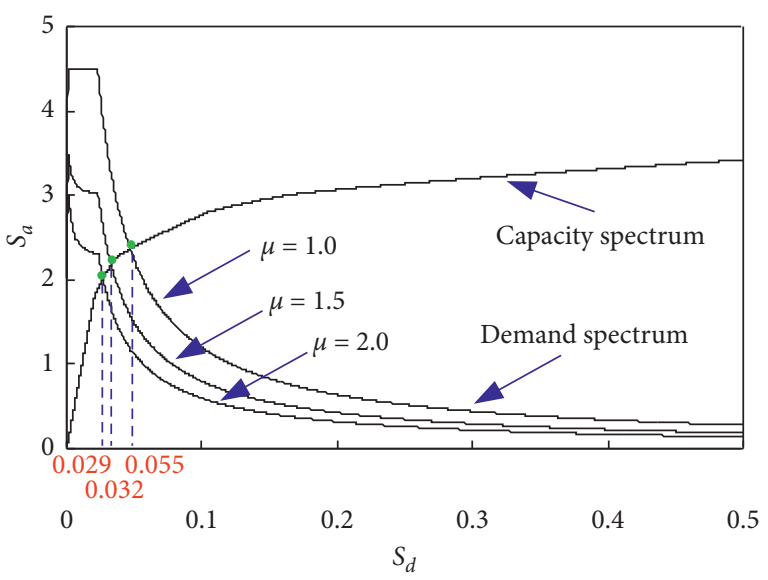

Figure 7: Analysis process of the simplified prediction method corresponding to PGA $=0.2 \mathrm{~g}$.

\section{Parametric Analysis of Calculation Accuracy of Simplified Prediction Procedure}

The results from the foregoing three cases show that the simplified prediction method using RSP is a good predictor of the seismic displacement of irregular-continuous bridges. However, just like other simplified methods, it still is a semitheoretical and semiempirical method. Some assumptions are adopted in the theoretical analysis; therefore, it is not enough to verify the efficiency of the simplified prediction method using RSP based on only three cases. Carrying out more parametric analyses is necessary to ensure the validity of the simplified prediction method using RSP before applying its theories to simplified displacement-based seismic design of irregular-continuous bridges.

6.1. Bridge Structure and Seismic Input. Three cases of continuous bridges are identified as the reference of analysis, whose geometry shapes and section properties of girders and piers are shown in Figure 1 and Table 1, respectively. Based on the three cases, some parameters are changed to produce more combinations as shown in Table 2. The combination rule changes one parameter by keeping the other parameters the same. As the three cases are the simplified model of the true bridges, the new models of Table 2, obtained by changing only one parameter, are reasonable to include many practical bridges. They can be used for numerical simulation. 


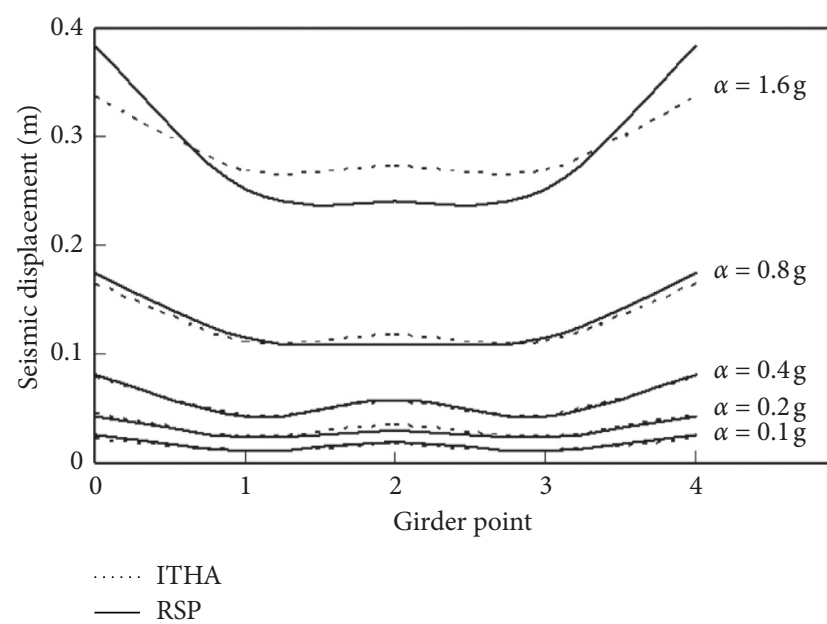

(a)

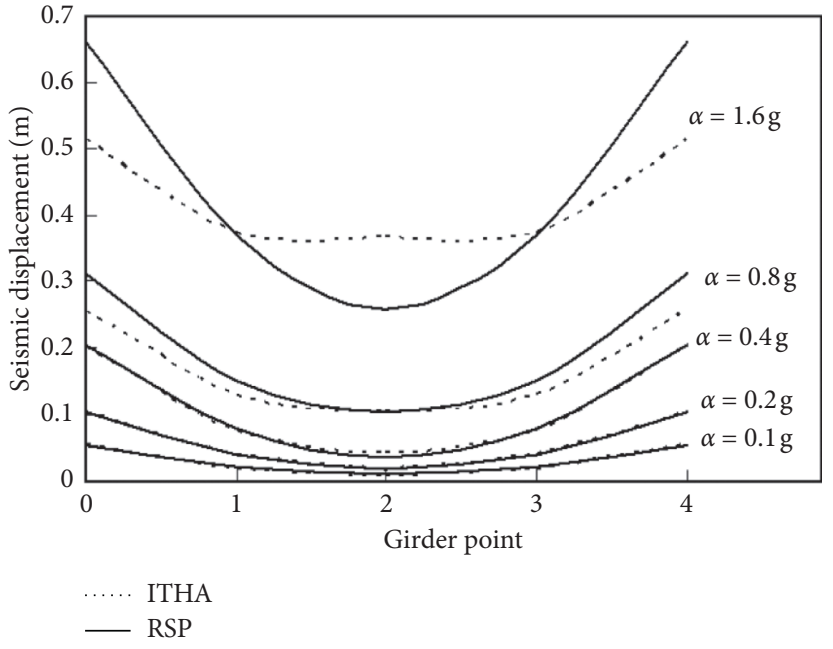

(b)

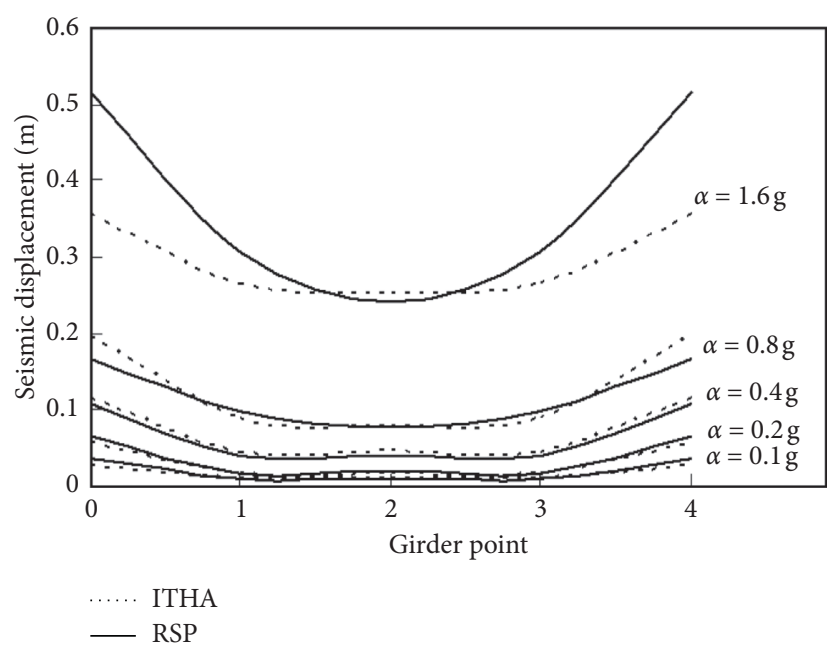

(c)

FIGURE 8: Comparison of seismic displacement by the ITHA and simplified prediction method using RSP: (a) 051005 bridge, (b) 100510 bridge, and (c) 050505 bridge.

Based on Table 2 and to satisfy the study requirements of this paper, a majority of cases are obtained with 69 symmetrical bridges, selected as the study object of the parametric analysis.

When earthquake load is concerned, the simplified prediction method using RSP and ITHA adopt the inelastic demand spectrum and seven accelerograms, respectively, which are all corresponding to the elastic response spectrum as shown in Figure 2(a), and PGA adopts $0.1 \mathrm{~g}, 0.2 \mathrm{~g}, 0.4 \mathrm{~g}$, and $0.8 \mathrm{~g}$, respectively.

6.2. Numerical Results. As for each bridge model, the simplified prediction method using RSP and ITHA are used to calculate its seismic displacement, respectively. The ratios of the displacement values of the girder points $0,1,2,3$, and 4 in Figure 1 calculated from RSP to that of ITHA are shown in Figure 9.

According to Figure 9, when compared to the results of ITHA, the simplified prediction method using RSP can obtain the reasonable and conservative seismic displacement. The average values of these ratios are 1.03, 1.05, 1.09, and 1.15 when $\mathrm{PGA}=0.1 \mathrm{~g}, 0.2 \mathrm{~g}, 0.4 \mathrm{~g}$, and $0.8 \mathrm{~g}$, respectively. The relative error of the simplified prediction method using RSP increases as PGA increases.

\section{Procedure of Simplified Displacement-Based Seismic Design}

The displacement is the soul in the whole procedure of the displacement-based seismic design method to keep the balance between target displacement and seismic displacement demand. This can effectively control the structure's seismic damage. This procedure has been achieved by using an ITHA method but consumes too long computing time [34]. The simplified prediction method using RSP simplifies the calculation of seismic displacement demand of bridges and saves the computing time. This section will discuss how to apply the simplified prediction method using RSP to the 
TABLE 2: Changing parameters of girder and piers.

\begin{tabular}{|c|c|c|}
\hline $\begin{array}{l}\text { Member } \\
\text { type }\end{array}$ & Variables & Parameter values \\
\hline \multirow{4}{*}{ Girder } & Lateral moment of inertia $\left(\mathrm{m}^{4}\right)$ & $20,40,80$, and 160 \\
\hline & Polar moment of inertia $\left(\mathrm{m}^{4}\right)$ & $7,14,28$, and 56 \\
\hline & Section area $\left(\mathrm{m}^{2}\right)$ & $3.5,7,14$, and 28 \\
\hline & Single span length $(\mathrm{m})$ & $20,40,80$, and 160 \\
\hline \multirow{3}{*}{ Pier } & Section area $\left(\mathrm{m}^{2}\right)$ & $1.0 \mathrm{~m} \times 1.0 \mathrm{~m}, 1.5 \mathrm{~m} \times 1.5 \mathrm{~m}, 2.0 \mathrm{~m} \times 2.0 \mathrm{~m}$, and $2.5 \mathrm{~m} \times 2.5 \mathrm{~m}$ \\
\hline & $\begin{array}{l}\text { Area ratio of longitudinal } \\
\text { reinforcement }\end{array}$ & $0.4 \%, 0.8 \%, 1.2 \%$, and $1.6 \%$ \\
\hline & Height distribution of piers & $\begin{array}{l}\text { Pier2\# varies as } 5 \mathrm{~m}, 10 \mathrm{~m} \text {, and } 15 \mathrm{~m} \text {, while pier } 1 \# \text { equals to pier } 3 \# \text { and varies as } 5 \mathrm{~m}, 10 \mathrm{~m} \text {, } \\
\qquad 15 \mathrm{~m} \text {, and } 20 \mathrm{~m} \text { synchronously }\end{array}$ \\
\hline
\end{tabular}

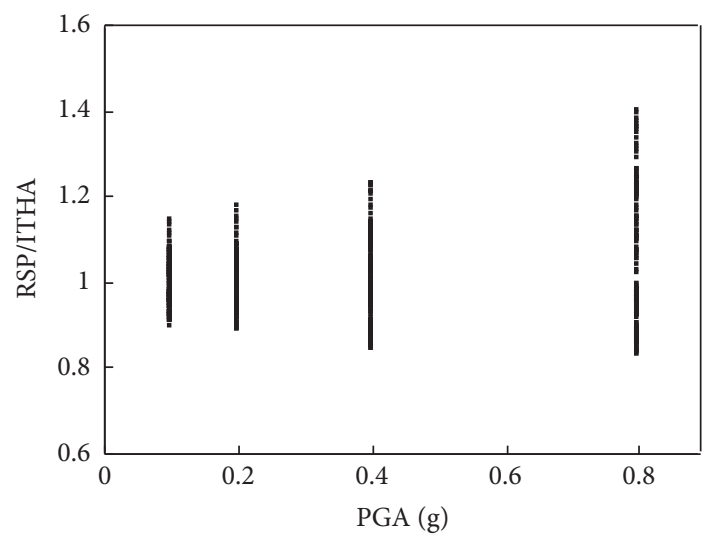

FIGURE 9: Ratio of seismic displacement of the simplified prediction method using RSP to that of ITHA.

displacement-based seismic design of the irregular-continuous bridges, especially for equilibrium iteration of target displacement and seismic displacement demand (Figure 10).

7.1. Target Displacement. Irregular-continuous bridges can be designed according to two design levels of $E 1$ and $E 2$ :

(1) As for the design level of small earthquake $E 1$, main parts of the structure only require little damage, i.e., the maximum section curvature $\varphi_{E 1}$ of main ductile members should be less than the corresponding yield curvature $\varphi_{y}$. The force-based seismic design can then be applied, but this is not the topic of this paper.

(2) In terms of the design level of large earthquake E2, the structure can have severe damage without collapsing or causing other fatal damage, i.e., the maximum section curvature $\varphi_{E 2}$ of main ductile members should be larger than the corresponding yield curvature $\varphi_{y}$ and not exceed the permitted limit curvature $\varphi_{u}$. The displacement-based seismic design can then be used, and this is the topic of this paper.

Under the design level of large earthquake E2, the displacement-based seismic design using a nonlinear static method will be proposed on the irregular-continuous bridges in this section and the following sections. First, how to obtain the target displacement of the irregular-continuous bridges is listed as follows:
(1) FEM of the bridge is built with experience-guided pier size and reinforcement arrangement, which is also achieved by the force-based seismic design under the design level of small earthquake E1. It is seen as the preliminary scheme of the design level of large earthquake E2, which will be continuously optimized in the following process. The FEM is used to obtain the response spectrum load distribution and carry out the following pushover analysis.

(2) The structure is pushed by the response spectrum load distribution, and the curvature of the most dangerous section of the first yielding pier is monitored. The general displacement $u_{r}$, yielding displacement $\Delta_{y}$, and ultimate displacement $\Delta_{u}$ of the whole bridge system, represented by the girder point 0 in Figure 1, are obtained when the monitored curvature reaches $\varphi_{y}$ and $\varphi_{u}$, respectively.

(3) The corresponding general displacement $S_{d}$, yield displacement $S_{d y}$, and limit displacement $S_{d u}$ of the capacity spectrum are calculated according to $S_{d}=u_{r} / c_{i}, S_{d y}=\Delta_{y} / c_{i}$, and $S_{d u}=\Delta_{u} / c_{i}$, respectively. $c_{i}$ refers to the coefficient of displacement shape using the girder point 0 in Figure 1 and equation (9) for the elastic state of the bridge.

7.2. Check of Preliminary Scheme. The capacity coefficient $\mu_{c}$ is calculated by $\mu_{c}=S_{d u} / S_{d y}$. The coefficient $\mu_{d E 2}$ corresponding to the inelastic demand spectrum of $E 2$ design level is set to be $\mu_{d E 2}=\mu_{c}$. When the capacity spectrum and the inelastic demand spectrum are drawn in the same figure, as shown in Figure 11, the actual seismic displacement of $E 2$ design level situates at $S_{d 2} \sim S_{d u}$. On this basis, there are two possibilities:

(1) If $S_{d u} \approx S_{d 2}$, the preliminary scheme will be satisfactory for E2 design level

(2) Under other conditions, a new scheme should be chosen

7.3. New Scheme. The bridge pier should be redesigned if the former scheme is not satisfactory, i.e., the case (2) in Section 7.2. Specify $S_{a n}=S_{a n 2}+\left(S_{a u}-S_{a 2}\right)$, in which all the piers yield when $S_{a u}$ is arrived since the structure is pushed until $S_{a}$ does not dramatically increase. In fact, all the piers will not yield at the same time under a special ground motion if 


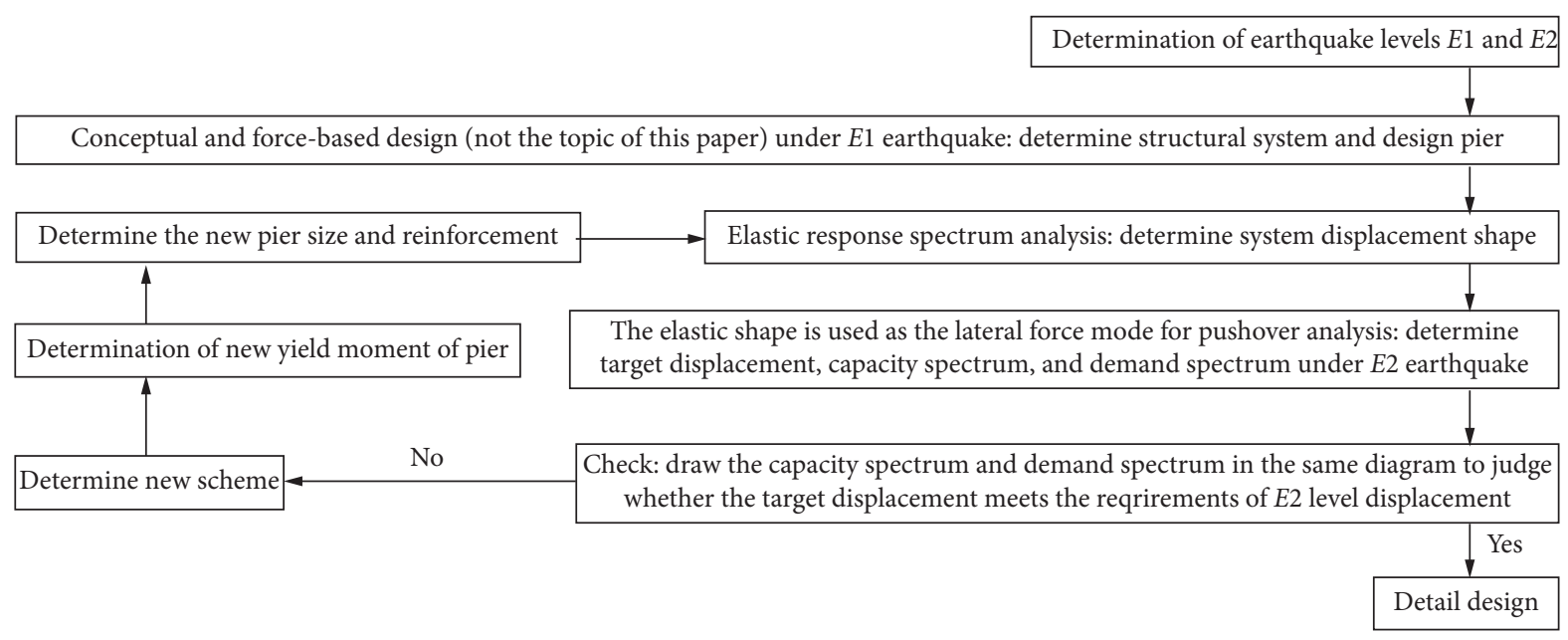

FIGURE 10: Displacement-based seismic design process using a nonlinear static method.

the piers have different length. However, when the ground motion continuously increases, the different piers will gradually enter the yield state such as the capacity spectrum in Figure 11. Finally, all the piers yield if the ground motion is large enough, and this state corresponds to $S_{a u}$ on the capacity spectrum in Figure 11. The state that all the piers yield can help to distribute the resultant force to each pier in the following process.

Therefore, the total inertial force of the new scheme after all the piers yield is $F_{g}=m_{g} S_{a n} . F_{g}$ includes all of the shear force at piers and abutments. The sum of shear force at each pier can be denoted by $F_{p}=F_{g}-F_{a}$, and $F_{p}$ is expressed by equation (13), where $F_{a}$ refers to the sum of shear force at abutments, and $F_{p n}$ is the shear force of the $n$ pier.

In many cases, bridge piers are often designed with the same cross section and the same reinforcement ratio. A principle of the same yield bending moment of each pier can be followed to distribute $F_{p}$ and calculate the yield bending moment $M_{y}$ of each pier as shown in the former expression of equation (14), where $h_{n}$ is the length of the $n$ pier. If the bridge piers are designed with different cross sections or different reinforcement ratios, other special but simple relations can be written as shown in the latter expression of equation (14). The yield bending moment $M_{y}$ calculated by equation (14) can be used to design the new cross section and reinforcement of piers,

$$
\begin{gathered}
F_{p 1}+F_{p 2}+F_{p 3}+\cdots+F_{p n}=F_{p}, \\
M_{y}=F_{p 1} h_{1}=F_{p 2} h_{2}=F_{p 3} h_{3}=\cdots=F_{p n} h_{n},
\end{gathered}
$$

or other special relations

7.4. Final Scheme. The sections above are repeated. The scheme that satisfies the requirement of $S_{d u} \approx S_{d 2}$ is the final scheme, because the limit displacement $S_{d u}$ of the capacity spectrum line and the inelastic demand spectrum line has the same ductility coefficient and the two lines just intersect at the point of $S_{d u}$. After the piers are designed based on equations (13) and (14), other detailed designs of the stirrup

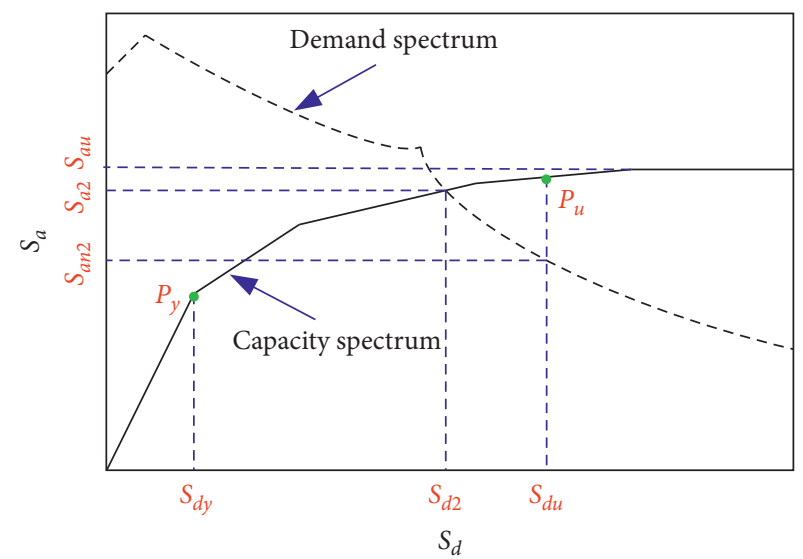

Figure 11: Check of design scheme.

of piers, the foundation, and the bearing can then be executed under the principle of capacity protection, which is not the topic of this paper.

\section{Verification Case of the Simplified Displacement-Based Seismic Design Procedure}

As to better describe the procedure of the foregoing displacement-based seismic design, a relatively simple irregular-continuous bridge is selected to carry out the displacement-based seismic design. It is then further checked by ITHA.

8.1. Introduction of Case. The known conditions are as follows:

(1) The first bridge with a total mass $2912 t$ of the superstructure in Figure 1 is selected as the design case

(2) Earthquake load adopts the response spectrum for soil profile III in Chinese criteria (JTJ 004-89) as shown in Figure 2(a), and PGA of E2 design level adopts $0.4 \mathrm{~g}$ 


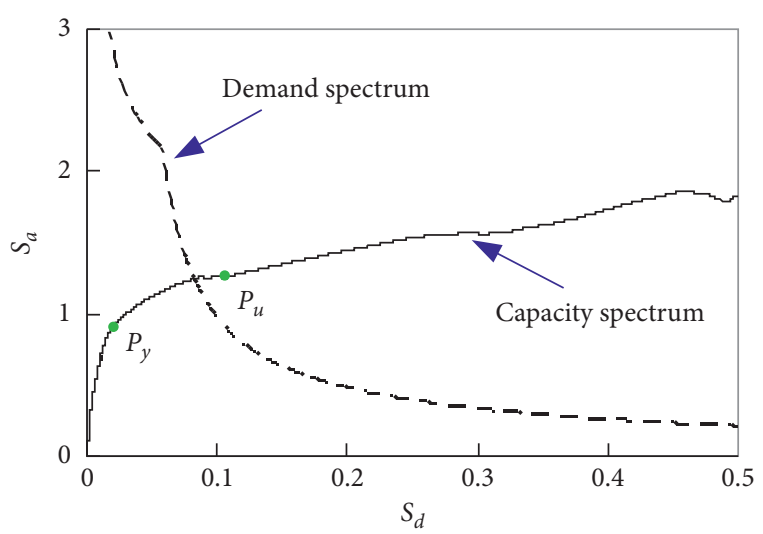

(a)

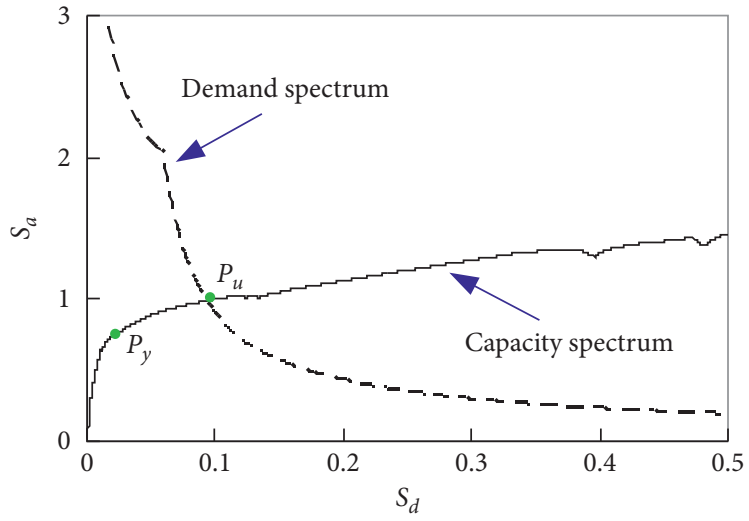

(b)

FIGURE 12: Check of design scheme: (a) preliminary scheme and (b) new scheme.

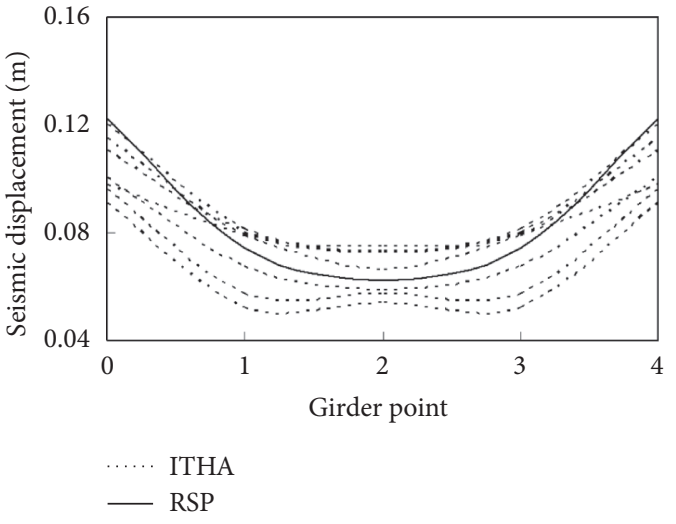

(a)

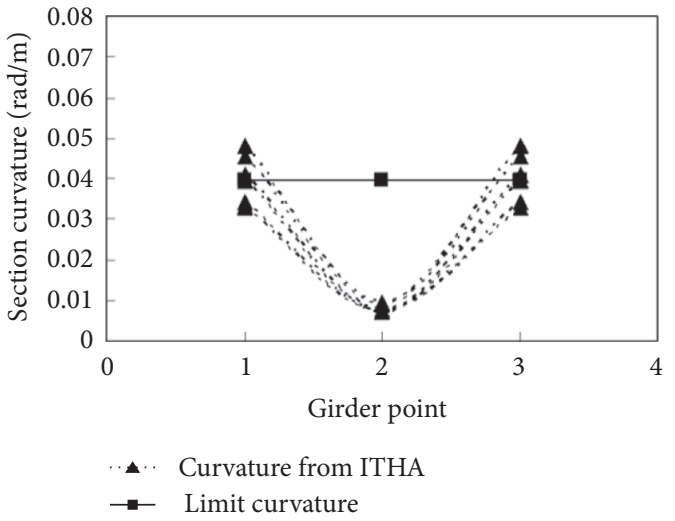

(b)

FIGURE 13: Check of design result: (a) seismic displacement calculated by RSP and ITHA and (b) curvature of the pier base section.

Note that the pier cross section and the reinforcement are unknown and need further design based on the displacement-based seismic design procedure.

8.2. Design Procedure. The preliminary pier scheme can be obtained by the conceptual design, the experience-guided design, or the force-based seismic design under the design level of small earthquake E1; however, this is not the topic of this paper. In this section, the cross section of the preliminary pier is assumed and given by $1.2 \mathrm{~m} \times 1.2 \mathrm{~m}$ with a longitudinal reinforcement ratio of $1.2 \%$.

FEM of the above bridge is the preliminary scheme, built in OpenSees program. According to the material strain capacity, the curvature information of the pier section is $\varphi_{y}=0.00273 \mathrm{rad} / \mathrm{m}$ and $\varphi_{u}=0.0394 \mathrm{rad} / \mathrm{m}$, and the latter of which corresponds to a collapse prevention state but has a safety factor of 2.0 according to Chinese criteria. When the whole bridge structure is pushed by the response spectrum load distribution, the curvature of the most dangerous section of the first yield $5 \mathrm{~m}$ pier and the displacement of the girder point 0 in Figure 1 are monitored. The displacement of $\Delta_{y}$ and $\Delta_{u}$ of the whole bridge system, represented by the displacement of the girder point 0 in Figure 1, is obtained when the monitored curvature reaches $\varphi_{y}$ and $\varphi_{u}$, respectively. The corresponding displacement information of the capacity spectrum is $S_{d y}=\Delta_{y} / c_{i}=0.0213 \mathrm{~m}$, $S_{d u}=\Delta_{u} / c_{i}=0.1077 \mathrm{~m}$, and $\mu_{c}=S_{d u} / S_{d y}=5.06$. The capacity spectrum represents the global measures of ductility, because it is obtained by pushing the whole bridge structure. It also represents the local measures of ductility, because it monitors the most strained $5 \mathrm{~m}$ pier and puts the corresponding indexes $S_{d y}$ and $S_{d u}$ in Figure 12 .

The demand spectrum of the E2 design level is built based on the assumption of $\mu_{d E 2}=\mu_{c}$, and it corresponds to a collapse prevention state of the global measures of ductility controlled by the $5 \mathrm{~m}$ pier. The combination of the capacity spectrum and demand spectrum is shown in Figure 12(a). Because $S_{d u}>S_{d 2}$ in Figure 12(a) being as well as that in Figure 11, the preliminary scheme is so safe that it needs to decrease the pier cross section or the longitudinal reinforcement ratio.

From $\quad$ Figure 12(a), $\quad S_{a n 2}+\left(S_{a u}-S_{a 2}\right)$ $=0.8759+(1.8671-1.1560)=1.5869 \mathrm{~m} / \mathrm{s}^{2}, \quad$ i.e., $S_{a n}=1.5869 \mathrm{~m} / \mathrm{s}^{2}$ for the new scheme, and the corresponding total inertia force of the new scheme is 
$F_{g}=2912 \times 1.5869=4621 \mathrm{kN}$. Note that piers almost support the total inertia force, since the abutment bearing is bidirectional sliding only taking a small amount of inertia force. According to the equal yield moment principle, the shear force $F_{p n}$ of three piers is $1852.183 \mathrm{kN}, 916.635 \mathrm{kN}$, and $1852.183 \mathrm{kN}$, respectively, based on equations (13) and (14), and the yield moment $M_{y}$ of each pier is $5171.033 \mathrm{kN} \cdot \mathrm{m}$. Therefore, in the new scheme in Figure 12(b), the cross section of the pier remains unchanged and the longitudinal reinforcement ratio decreases to $0.866 \%$ based on the pier yield moment of $M_{y}=5171.033 \mathrm{kN} \cdot \mathrm{m}$.

The combination of the capacity spectrum and the demand spectrum of the new scheme is shown in Figure 12(b). The result shows $S_{d u} \approx S_{d 2}$, which implies that the capacity spectrum line and the demand spectrum line just intersect at the point of $S_{d u}$ and satisfies the requirement of seismic design. Consequently, the scheme can be chosen as the final one.

8.3. Check of Design Result. To check the validity of the design result, the final scheme is calculated by ITHA. The accelerograms in Section 2 are chosen as the seismic input, and PGA adopts $0.4 \mathrm{~g}$. The seismic displacement calculated by the simplified prediction method using RSP and ITHA is shown in Figure 13(a). The check of target curvature of the pier base section is shown in Figure 13(b).

Figure 13(a) shows that the seismic displacement from the simplified prediction method using RSP is close to that from ITHA.

Figure 13(b) shows that the base section curvatures of the two short piers reach the limit value, and the base section curvature of the long pier is much less than the limit value. Therefore, the seismic design of the final scheme is controlled by the short pier's deformation capacity of $E 2$ design level.

The check results show that the seismic design result is proper and correct.

\section{Conclusion}

By taking one common type of irregular-continuous bridges with quasi-regular geometry, the building procedures of the capacity spectrum and the demand spectrum are discussed. As a result, the simplified displacement-based seismic design procedure is advanced. Thus, conclusions include the following:

(1) The pushover curve resulted from a pushover analysis can be selected as the capacity spectrum of one common type of irregular-continuous bridges. In the pushover analysis, the girder end point 0 is selected as the displacement reference point, and the displacement shape from the response spectrum analysis is used to determine the load distribution.

(2) By combining the capacity spectrum and the inelastic demand spectrum, the seismic displacement demand can be properly predicted for one common type of irregular-continuous bridges.
(3) After several iterations of the combination of the capacity spectrum and the inelastic demand spectrum, the simplified displacement-based seismic design of one common type of irregular-continuous bridges can be achieved.

It is noted that the above proposed nonlinear static procedure is only applicable for the common irregularcontinuous bridges with similar characteristics of those used in the case study and those used for the parametric analysis. Those bridges have many regular factors and only few irregular factors, leading to the obvious influence of high modes. And the higher mode effects are mild for the fourspan bridges, which improves the accuracy of the conventional force-based single-load pattern pushover analysis. It needs further investigation whether the above proposed nonlinear static procedure extends beyond to what was presented for the designed bridge in this paper [35, 36]. Furthermore, the above proposed nonlinear static procedure is a little complex, such as using a FEM model to help analysis. It needs investigation about how to further simply the proposed nonlinear static procedure in the future.

\section{Data Availability}

The data used to support the findings of this study are included within the article. The data include the structural parameters, ground motion inputs, calculation methods, and calculation results.

\section{Conflicts of Interest}

The authors declare that they have no conflicts of interest.

\section{Acknowledgments}

This paper was supported by the National Natural Science Foundation of China under grant nos. 51778635 and 51778630 , the Natural Science Foundation of Hunan Province under grant no. 2019JJ40386, and the InnovationDriven Plan in Central South University under grant no. 20200017050004. These financial supports are gratefully acknowledged.

\section{References}

[1] AASHTO, AASHTO LRFD Bridge Design Specifications, AASHTO, Washington, DC, USA, 4th edition, 2007.

[2] H. R. Ahmadi, N. Namdari, M. S. Cao, and M. Bayat, "Seismic investigation of pushover methods for concrete piers of curved bridges in plan," Computers and Concrete, vol. 23, no. 1, pp. 1-10, 2019.

[3] T. S. Paraskeva, A. J. Kappos, and A. G. Sextos, "Extension of modal pushover analysis to seismic assessment of bridges," Earthquake Engineering \& Structural Dynamics, vol. 35, no. 10, pp. 1269-1293, 2006.

[4] M. Jafari and M. Soltani, "A stochastic adaptive pushover procedure for seismic assessment of buildings," Earthquakes and Structures, vol. 14, no. 5, pp. 477-492, 2018.

[5] J. Luo, L. A. Fahnestock, and J. M. LaFave, "Nonlinear static pushover and eigenvalue modal analyses of quasi-isolated 
highway bridges with seat-type abutments," Structures, vol. 12, pp. 145-167, 2017.

[6] A. M. Reinhorn, "Inelastic analysis techniques in seismic evaluations," in Proceedings of the International Workshop on Seismic Design Methodologies for the Next Generation of Codes, pp. 277-287, Bled, Slovenia, 1997.

[7] A. R. Ghotbi, "Modal pushover analysis of skewed bridgescase study of jack tone road on-ramp overcrossing," KSCE Journal of Civil Engineering, vol. 20, no. 5, pp. 1948-1957, 2016.

[8] A. K. Chopra and R. K. Goel, "Evaluation of modal and FEMA pushover analyses: SAC Buildings," Earthquake Spectra, vol. 20, pp. 225-254, 2004.

[9] K. Shakeri, K. Tarbali, and M. Mohebbi, "An adaptive modal pushover procedure for asymmetric-plan buildings," Engineering Structures, vol. 36, pp. 160-172, 2012.

[10] T. S. Paraskeva and A. J. Kappos, "Further development of a multimodal pushover analysis procedure for seismic assessment of bridges," Earthquake Engineering and Structure Dynamics, vol. 39, pp. 211-222, 2010.

[11] M. N. Aydinoglu, "An improved pushover procedure for engineering practice: incremental response spectrum analysis IRSA," in Proceedings of the International Workshop Performance-Based Seismic Design Concepts and Implementation, no. 5, pp. 345-356, Bled, Slovenia, 2004.

[12] T. Isakovic and M. Fischinger, "Higher modes in simplified inelastic seismic analysis of single column bent viaducts," Earthquake Engineering and Structure Dynamics, vol. 35, pp. 95-114, 2006.

[13] B. Wei, "Study of the applicability of modal pushover analysis on irregular continuous bridges," Structural Engineering International, vol. 21, no. 2, pp. 233-237, 2011.

[14] M. R. Falamarz-Sheikhabadi and A. Zerva, "Effect of numerical soil-foundation-structure modeling on the seismic response of a tall bridge pier via pushover analysis," Soil Dynamics and Earthquake Engineering, vol. 90, pp. 52-73, 2016.

[15] M. J. Kowalsky, M. J. N. Priestley, and G. A. Macrae, "Displacement-based design of RC bridge columns in seismic regions," Earthquake Engineering \& Structural Dynamics, vol. 24, no. 12, pp. 1623-1643, 1995.

[16] M. J. Kowalsky, "Direct displacement-based design: a seismic design methodology and its application to concrete bridges," Doctoral dissertation, University of California at San Diego, San Diego, CA, USA, 1997.

[17] M. J. Kowalsky, "A displacement-based approach for the seismic design of continuous concrete bridges," Earthquake Engineering \& Structural Dynamics, vol. 31, no. 3, pp. 719747, 2002.

[18] M. J. N. Priestley, G. M. Calvi, and M. J. Kowalsky, Displacement-Based Seismic Design of Structures, IUSS Press, Vienna, Austria, 2007.

[19] A. J. Kappos, I. G. Gidaris, and K. I. Gkatzogias, "Problems associated with direct displacement-based design of concrete bridges with single-column piers, and some suggested improvements," Bulletin of Earthquake Engineering, vol. 10, no. 4, pp. 1237-1266, 2012.

[20] A. J. Kappos, K. I. Gkatzogias, and I. G. Gidaris, "Extension of direct displacement-based design methodology for bridges to account for higher mode effects," Earthquake Engineering \& Structural Dynamics, vol. 42, no. 4, pp. 581-602, 2013.

[21] Y. Fahjan and Z. Ozdemir, "Scaling of earthquake accelerograms for non-linear dynamic analysis to match the earthquake design spectra," in Proceedings of the 14th World Conference on Earthquake Engineering, Beijing, China, 2008.

[22] H. Dwairi and M. Kowalsky, "Inelastic displacement patterns in support of displacement-based design for multi-span bridges," in Proceedings of the 13th World Conference on Earthquake Engineering, Vancouver, Canada, 2004.

[23] C. Perdomo, R. Monteiro, and H. Sucuoğlu, "Generalized force vectors for multi-mode pushover analysis of bridges," Bulletin of Earthquake Engineering, vol. 15, no. 12, pp. 5247-5280, 2017.

[24] S. Mazzoni, F. McKenna, and M. H. Scott, OpenSees Command Language Manual, Pacific Earthquake Engineering Research, University of California, Oakland, CA, USA, 2007.

[25] B. Wei, Z. L. Hu, X. H. He, and L. Z. Jiang, "Evaluation of optimal ground motion intensity measures and seismic vulnerability analysis of multi-pylon cable-stayed bridge with super-high piers in mountainous areas," Soil Dynamics and Earthquake Engineering, vol. 129, 2020.

[26] B. Wei, C. Li, and X. He, "The applicability of different earthquake intensity measures to the seismic vulnerability of a high-speed railway continuous bridge," International Journal of Civil Engineering, vol. 17, no. 7, pp. 981-997, 2019.

[27] P. Fajfar, "A nonlinear analysis method for performancebased seismic design," Earthquake Spectra, vol. 16, no. 3, pp. 573-592, 2000.

[28] M. Kohrangi, R. Bento, and M. Lopes, "Seismic performance of irregular bridges-comparison of different nonlinear static procedures," Structure and Infrastructure Engineering, vol. 11, no. 12, pp. 1632-1650, 2015.

[29] R. Pinho, R. Monteiro, C. Casarotti, and R. Delgado, "Assessment of continuous span bridges through nonlinear static procedures," Earthquake Spectra, vol. 25, no. 1, pp. 143-159, 2009.

[30] N. M. Newmark and W. J. Hall, "Seismic design criteria for nuclear reactor facilities," in Proceedings of the 4th World Conference on Earthquake Engineering, Santiago, Chile, 1969.

[31] G. H. Cui, C. G. Liu, X. X. Tao, and X. M. Chen, "Seismic safety evaluation of bridge structures based on inelastic spectrum method," in Proceedings of the 14th World Conference on Earthquake Engineering, Beijing, China, 2008.

[32] E. Miranda, "Inelastic displacement ratios for structures on firm sites," Journal of Structural Engineering, vol. 126, no. 10, pp. 1150-1159, 2000.

[33] M. Ozgenoglu and Y. Arıc1, "Comparison of ASCE/SEI Standard and modal pushover-based ground motion scaling procedures for pre-tensioned concrete bridges," Structure and Infrastructure Engineering, vol. 13, no. 12, pp. 1609-1623, 2017.

[34] A. J. Kappos and A. Manafpour, "Seismic design of R/C buildings with the aid of advanced analytical techniques," Engineering Structures, vol. 23, no. 4, pp. 319-332, 2001.

[35] Y. Xia, L. M. Chen, H. Y. Ma, and D. Su, "Experimental and numerical study on shear studs connecting steel girder and precast concrete deck," Structural Engineering and Mechanics, vol. 71, no. 4, pp. 433-444, 2019.

[36] S. Wu, "Unseating mechanism of a skew bridge with seat-type abutments and a simplified method for estimating its support length requirement," Engineering Structures, vol. 191, pp. 194-205, 2019. 